One of the lessons of the war is the wonderful saving in time and man-power that was effected by institutional treatment from the beginning of such cases as corneal ulcer, iritis, etc. This lesson should be applied to civilian practice and to civil hospital patients. At present the triumphs of in-patient treatment are obtained with cataract and glaucoma patients who have often come to the end of their active life. There is a tendency to fill the beds with operation cases, so that no room is available for many cases requiring treatment. Institutional treatment at an early stage might save many a clear pupillary area of the cornea, and might leave an eye affected with iritis ready to resist any subsequent recurrence, unhampered even by a single adhesion. By sending these cases to be treated in a haphazard way in their own homes both time and power are lost.

Should not all leading 'ophthalmic hospitals now have convalescent homes, such as the army hospitals have had ${ }^{\bullet}$ abroad, where complete recovery can take place in fresh air, and under skilled attention, combined with adequate occupation and amusement ? If these homes were established to receive the convalescents the present hospitals would still be able to restore sight to the aged by operation, while all the cases in the acute stages of disease could at once, without overcrowding, be admitted for institutional treatment and passed on to the convalescent home for complete recovery under more salubrious surroundings than can be afforded by city hospitals.

Such homes may be difficult to obtain at the moment owing to expense, but it would be well to have a complete and concrete policy to put forward should the voluntary hospitals, in the near future, be taken over wholly or in part by the State.

\title{
REPORT OF THE COUNCIL OF BRITISH OPHTHALMOLOGISTS
}

\section{On the visual requirements of persons licensed to drive mechanically propelled vehicles on public roads}

THE following report is the result of an enquiry conducted during the early months of the year, 1919, by a Committee appointed by the Council of British Ophthalmologists. The Council was impressed by the increasing number of accidents caused by motor traffic, and desired to ascertain to what extent these might be due to defective vision on the part of drivers. Unfortunately, as will be seen from the report, statistics on this point are meagre. As matters at present stand, the only qualification required for obtaining a licence to drive a motor vehicle, other than a public conveyance, is that the applicant must be 17 years of age, and it is 
a fact that a blind man has obtained a licence. The problem before the Council has been to ascertain the types of visual defect which may interfere with or delay a driver's power of taking any action necessary to prevent accidents, and, as far as possible, to determine a standard which will not exclude drivers whose visual defect is such as not to interfere with their capacity for driving with safety.

The report is divided into five parts :

I.-The existing conditions under which licences are granted to drivers of various forms of mechanically propelled vehicles in this and other countries.

II.-The number of accidents occasioned annually by mechanically propelled vehicles in London.

III.-The various kinds of visual defects in motor-drivers from which accidents may arise :-

(1) Blindness in, or loss of one eye.

(2) Conditions necessitating the habitual use of spectacles.

(3) Defective acuity of vision both with and without spectacles.

(4) Restricted fields of vision; night-blindness.

(5) The presence of diplopia or squint.

IV.-Proposed scheme of vision testing for licences.

V.-Summary of recommendations.

1.- The existing conditions under which licences are granted to drivers of various forms of mechanically propelled vehicles in this and other countries

The United Kingdom.-There are at present two forms of Licence granted in this country in connection with motor driving, a County Council or Borough Council Licence and a Public Carriage Police Licence.

\section{1.-County Council or Borough Council Licence}

This is granted by County Councils or Borough Councils to any applicant over 17 years of age on payment of a fee of $5 \mathrm{~s}$. It is granted merely for the purpose of registration; it calls for no investigation of the applicant's vision or fitness to drive; and it is liable to endorsement or suspension in a Magistrate's Court for offences under the Motor Car Act.

\section{2.-Public Carriage Police Licence}

This is granted by the Police to drivers of public motor vehicles, hackney motor cabs, motor omnibuses, and tramway cars.

In January, 1916, a Committee was appointed by the Home Secretary to consider and report on the licensing of partially disabled 
men as drivers of public motor vehicles, and the following is taken from the recommendations with regard to "Loss of Eye":-

"The views which we have heard in evidence are perhaps a little "less divergent in this instance. The witnesses have been "practically unanimous in the opinion that the right eye is more " important than the left eye in the case of motor car driving. The " main reason is that the driver who had lost his right eye would be "compelled to turn his head completely round should he wish to "see if any traffic were trying to overtake him, and he would also "be in great danger of causing an accident by turning his vehicle " to the off side across incoming traffic. The sideward vision of the "right eye is clearly of great importance. There is hardly a " dissentient voice as regards the absolute necessity for a sound right "eye. With tramcars, on the other hand, the possession of the left "eye is perhaps more important. As a rule tramlines are laid at the " middle of the road and the space for other traffic is on the near "or left side. Passengers approaching the vehicle are also coming "from that side. For these reasons a man could hardly be an "efficient or safe driver without his left eye; the right eye is, " however, also of considerable importance, and the medical adviser "of the London County Council stated that he would not accept " any man for service who had lost one eye."

"Assuming for a moment that men with only one eye were "licensed, the main dangers would be:

" (1) the limitation of the field of vision already mentioned;

“(2) the danger of being temporarily blinded through getting grit "or flies into the single sound eye.

"The driver would be compelled to stop at once and he might " possibly cause an accident in his blinded condition in bringing " the vehicle to a standstill.

"One of the witnesses suggested that the loss of an eye is a less "important handicap than the use of glasses, but we cannot accept "the view that the one-eyed man is safer than the man with "glasses.

"The medical adviser of the London General Omnibus Company

"laid great stress upon the importance of eyesight. He regards "equal and normal sight as essential in an omnibus driver, and "states that he would never admit a one-eyed man for service, " pointing out that in passing a, vehicle in a crowded thoroughfare, "the question of inches tells, and it is impossible for a man's " eyesight to be too good. We have given very close consideration " to this question of eyesight. We know that certain men can rise "superior to almost any physical disability, but we do not feel that " men who have suffered in this particular respect ought to be " encouraged to adopt a calling like motor driving, which requires " rather more than the average capacity. We are informed that the 
"licensing of a man with only one eye would not be altogether

" without precedent, as the Commissioner of Police, some years ago, " in sympathy with men already licensed who met with accidents " and lost an eye, decided to continue their licences. In these " circumstances, however, the men-being old hands-would " naturally be better equipped for driving a public vehicle than an " applicant without previous experience, and we are doubtful " whether such a decision would have been arrived at under present

" traffic conditions, and if the concession had not been limited to " certain special classes. We are of opinion that every man licensed " should have two eyes, and that one of them, at least, should be a "good and normal one. If the other eye were to some extent "defective, but the vision were fair, and the field of vision good, we "do not feel that this defect need be a bar, but we would not " recommend any concession beyond that.

" Being entirely convinced, our considered opinion is that-having " regard to the normal conditions of traffic in the Metropolis-licences " to drive motor cabs, motor omnibuses or tramway cars should not " be granted to men who have suffered the loss of an arm, hand, leg, " foot or eye. In the case of injury to one eye, provided the other " eye is sound and the injured eye retains fair vision, we think a "licence might be granted, each case being of course decided on "its merits."

The recommendations and report of the Maimed Drivers' Committee were approved by the Secretary of State, and consequently the Commissioner of Police in London feels bound by them in his capacity as Licensing Authority at the present time. The terms "normal eye" and "fair vision". are not defined in the report, but the Licensing Authorities have adopted as their interpretation of the term "normal eye" an eye with visual - acuity equal to $6 / 6$ and a full field of vision, and of the term "fair vision" visual acuity equal to $6 / 24$ and a full field of vision. In actual practice, all that is required is that the applicant for a police licence shall produce a certificate from any medical man stating that his sight is sufficient to enable him to drive with safety the vehicle for which he desires a licence. It is not necessary for the medical man to state what the applicant's visual acuity is, but should he do so, and should it be below the above standard, either the licence is refused, or the applicant is sent by the police to an ophthalmic surgeon for examination and report.

In some of the large provincial towns in England, such as Liverpool, Manchester, and Birmingham, we have ascertained that in no case is there any special test of vision, but that a taxicab driver, before a licence is granted, is sent out with an official deputed by the police to test his driving capacity. 
France.*-It is necessary for every driver of a motor-propelled vehicle to hold a licence ("Permis de conduire"). This can be obtained only after an examiner has satisfied himself that the driver is capable. An international pass can be obtained in London by a British subject wishing to take his car into France, but a similar examination has to be passed. In neither case is there any actual eyesight test.

In Paris there do not appear to be any special regulations concerning the granting of licences to drivers of taxi-autos. Persons applying for such licences must have the usual French "Permis de conduire," or driving licence, and when making their application must submit their birth certificates and identity papers. They have also to pass an examination as to their knowledge of the streets of Paris.

United States of America. †-Very few of the States comprising the United States of America make any reference to vision in their regulations for granting licences to drive motor vehicles. Such of them as do allude to the question do not state that any standard of vision is required or that any definite tests have been established: vague statements are made to the effect that eyesight of applicants must not be impaired or defective.

Various cities have, however, considered the question of vision in granting licences to taxi-cab drivers. In Chicago, for example, an applicant before being granted such a licence is required to have a certain standard of distant vision as tested by test types.

2.- The number of accidents occasioned annually by mechanically propelled vehicles in London

The following tables show the number of accidents known to the police to have occurred in the streets within the Metropolitan Police District during the years 1912 to 1917 (inclusive).

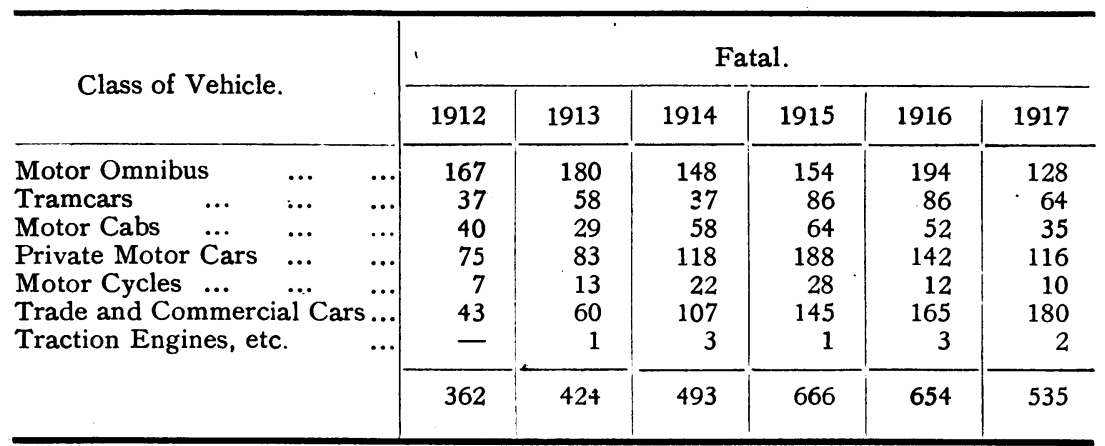

* We are indebted for this information to the Secretary of the Royal Automobile Club.

†We are indebted for this information to Dr. W. Campbell Posey, of Philadelphia, Dr. Frank Allport, of Chicago, and Dr. Gordon L. Berry, Field-Secretary of National Committee for the Prevention of Blindness, New York. 


\begin{tabular}{|c|c|c|c|c|c|c|}
\hline \multirow{2}{*}{ Class of Vehicle. } & \multicolumn{6}{|c|}{ Non-Fatal. } \\
\hline & 1912 & 1913 & 1914 & 1915 & 1916 & 1917 \\
\hline $\begin{array}{llll}\text { Motor Omnibus } & \ldots & \ldots \\
\text { Tramcars } & \ldots & \ldots & \ldots \\
\text { Motor Cabs } & \ldots & \ldots & \ldots \\
\text { Private Motor } & \text { Cars } & \ldots & \ldots \\
\text { Motor Cycles } & \ldots & \ldots & \ldots \\
\text { Trade and Commercial Cars } & \ldots \\
\text { Traction Engines, etc. }\end{array}$ & $\begin{array}{r}2,580 \\
2,303 \\
2,091 \\
2,821 \\
768 \\
395 \\
8\end{array}$ & $\begin{array}{r}3,255 \\
3,037 \\
1,948 \\
2,977 \\
1,133 \\
819 \\
14\end{array}$ & $\begin{array}{r}3,007 \\
3,171 \\
3,085 \\
3,682 \\
1,465 \\
1,218 \\
10\end{array}$ & $\begin{array}{r}2,572 \\
4,001 \\
2,251 \\
3,920 \\
1,696 \\
1,918 \\
8\end{array}$ & $\begin{array}{r}2,395 \\
3,913 \\
1,609 \\
3,242 \\
1,154 \\
2,189 \\
10\end{array}$ & $\begin{array}{r}1,743 \\
3,136 \\
1,172 \\
2,452 \\
840 \\
2,202 \\
\quad 6\end{array}$ \\
\hline & 10,966 & 13,183 & 14,683 & 16,366 & 14,592 & 11,551 \\
\hline
\end{tabular}

Though it will be observed that the annual number of fatal and non-fatal accidents had decreased during the years 1916 and 1917, it must be remembered that the number of hackney carriages plying for hire was considerably diminished during this period. In December, 1914, there were licensed :

$$
\text { Taxicabs, 7,260. Drivers, } 9,082
$$

In December, 1918 :

$$
\text { Taxicabs, 3,821. Drivers, 5,476 }
$$

One striking feature shown in these tables is the steady increase in the number of accidents, both fatal and non-fatal, caused by trade and commercial cars during the whole period dealt with, even during the last two years when the total number of accidents decreased. Less care has probably been taken in the selection of drivers for this class of vehicle than for any other.

These accidents are attributable to various causes. Having regard to the conditions under which licences to drive mechanically propelled vehicles are granted, there can be little doubt that defective eyesight of drivers is one cause.

\section{3.- The various kinds of visual defects in motor-drivers from which accidents may arise}

(1) Blindness in, or loss of one eye.-Persons who are blind in, or who have lost one eye, have a limitation of their field of vision, and can no longer see objects stereoscopically.

To compensate for the disadvantages occasioned by their limitation of field, those who have lost the sight of one eye generally learn to carry the head a little turned towards the blind side, so that the limitation becomes more equally apportioned on the two sides. They also in course of time instinctively acquire a habit of quickly moving the head towards the affected side, which enables them to mitigate to a considerable extent their disability.

Though, in motor-driving, stereoscopic vision is of some assistance in the judgment of distances, it is not the most important factor 
concerned, several others, such as parallax and aerial perspective, being of greater importance. Individuals who have never had the use of the two eyes are often good judges of distance.

The evidence which the Council had collected from drivers of mechanically-propelled vehicles who become blind in, or lost one eye, is in accordance with the above observations. They all considered themselves fully competent to drive, well able to take care of themselves when so employed, and capable of avoiding risks which woüld be likely to endanger the safety of others. Those who after cross-examination admitted having met with accidents, denied emphatically that such accidents resulted from their visual defect. Those who had lost the sight of the right eye, when questioned as to the difficulty of seeing on-coming traffic on the off-side, or traffic approaching from a cross-road on that side, did not admit having experienced any inconvenience. All had had a blind side for some considerable time and doubtless had acquired compensatory movements of the head. There is no doubt, however, that a person who had only recently lost the sight of an eye, particularly the right, would for a time experience considerable difficulty in such circumstances.

All the drivers dependent on the sight of one eye only who were interviewed, admitted that they might find themselves disabled in the event of a foreign body getting into that eye, a disability which could only be guarded against by the habitual use of goggles, though the risk of it might to some extent be lessened by the use of a wind screen.

2. Conditions necessitating the habitual use of spectacles. -The habitual use of spectacles by a driver of a mechanically propelled vehicle might prove a hindrance to him in one of the three following wavs :-

(a) By restriction of the field of vision.

(b) By reduction of the acuity of vision in dim lights.

(c) By the glasses becoming obscured either from the condensation of moisture (outside from mist, or inside from the eye), or from being bespattered with rain or dust.

(a) The amount of the restriction of the field of vision occasioned by ordinary spectacles would be very slight, much less than that produced by the use of goggles. Such evidence as the Committee has collected from motor drivers does not seem to show that the restriction of field caused by the use of ordinary spectacles has proved a source of danger.

(b) In transmission through glass loss of light occurs from absorption and also by reflection from the surfaces. In certain conditions of adaptation of the eyes to dim illumination, physical causes of this nature may more than counteract the beneficial effects of the correction of errors of refraction by spectacles. 
(c) In motor driving obscuration of glasses by moisture from eyes only occurs in the absence of freely circulating air between the eyes and the glasses. It is not likely to occur, therefore, with the use of ordinary spectacles, or of properly constructed goggles where ventilation holes are provided in the surrounding material.

Obscuration of spectacles from without by mist, rain, or dust, can to some extent be guarded against by adaptable screens, extending from an over-hanging canopy above and from the footboard below, but not meeting. Such screens are provided in taxicabs and in most large motor cars. The drivers of motor omnibuses and tramcars have even less protection.

3. Defective acuitv of vision both with or without spectacles.It is difficult to determine from the evidence at present available what degree of acuity of vision an individual needs if he is to drive a mechanically-propelled vehicle with safety.

Further valuable information as to the influence which defective vision has in the causation of motor accidents might be obtained if the Authorities were to institute an investigation into the visual capacity of drivers in a series of cases in which accidents have occurred.

In the Report of the Committee on the granting to partially disabled men of licences to drive public vehicles already quoted, it was laid down: "That every man licensed should have two eyes and "that one of them, at least, should be a good and normal one. If " the other eye were to some extent defective, but the vision were "fair, and the field of vision good, we do not feel that this defect " need be a bar, but we would not recommend any concession "beyond that."

The interpretation which the licensing authorities for hackney carriages in London put upon the terms " normal eye" and "fair vision" in the above Report, is as follows :

A " normal eye" is an eye with visual acuity $=6 / 6$ as tested with Snellen's test types well illuminated, and with a full field of vision as tested by hand movement.

The term, "fair vision," is visual acuity $=6 / 24$ as tested with Snellen's test types well illuminated and a full field of vision as tested by hand movement.

t: The evidence on which the "Maimed Drivers' Committee" based this part of its report was the expression of opinions by the witnesses examined and was not founded on definite instances of accidents occasioned by defective vision.

The standard of central acuity of vision required for chauffeurs by the Army is, without glasses, in one eye 6/18 and in the other 6/60, no distinction being made as to which eye should have the better vision (A.C.I. 664, 1918). Many motor drivers employed by the 
Army during the war had to drive heavy motor lorries along bad roads at night.

The Council have had a return of all the motor accidents occurring in the 1st and 2nd Transport Companies at Grove Park during the months of January and February, 1919, 36 in all. The vision of the drivers in these accidents was obtainable in 14 cases, and it was found that central acuity of vision in the better eye in more than half the cases equalled $6 / 6$, and in none of the cases was it less than 6/12. This evidence, for permission to use which the Council are indebted to General Sir J. H. Goodwin, K.C.B., D.G.A.M.S., shows that the accidents which occurred, in the cases investigated, could not be attributed to defect of vision.

The Council do not think, however, that the standard of central acuity of vision for motor drivers in the Army under war conditions, when there was a shortage of labour, can be taken as a suitable standard for motor drivers of public vehicles in civil life, in time of peace, when there is an ample supply.

(4) Restricted fields of vision and night blindness.-For the quick perception of on-coming traffic, or of objects approaching from either side, a full field of vision is the most important factor, rather than acute form sense in the centre of the field such as is tested by reading letters of different sizes in Snellen's test types.

It is from the stimulation of the peripheral portions of the retina that the approach of on-coming objects from behind, or from side turnings, is first perceived. It is, therefore, often the part of the retina which affords the earliest intimation of the approach of dangers which might culminate in collisions.

The presence of lowered acuity of vision in dim light, or of slow adaptation of the eyes from one light to another (" night blindness ") might prove very dangerous to drivers of mechanically-propelled vehicles which do not carry powerful head lights. They are conditions, therefore, likely to cause accidents in towns where the use of powerful head lights for motor vehicles is not permitted. The presence of a slight degree of night blindness is often difficult to detect without a very searching examination. For the purposes of motor driving the most practical test of a person's lightsense would be a trial trip at night, during which he should be required to show his capacity for steering a motor car in dim lights, and under varying conditions of illumination. This latter test would afford some criterion as to the time required for the eyes to adapt themselves from light of one degree of intensity to that of another.

(5) The presence of diplopia or squint.-A disordered movement of the eyes which causes a driver to see double must obviously be a serious source of danger in the steering of a mechanically propelled vehicle.

Disordered movements of the eyes may exist without double 
vision, the individual so affected using only one eye, suppressing the image formed by the other. Such individuals do not possess stereoscopic vision and are thus handicapped to some extent in their judgment of distances.

Disordered movements of the eyes causing one eye to turn inwards, "convergent squint," produce, besides the loss of stereoscopic vision, some limitation of the field of vision, on the side of the squinting eye.

\section{4.-Proposed scheme of vision-testing for licences}

Although it is desirable that some test should be made of the visual capacity for motor driving of every applicant for a licence (or renewal of licence), it is impracticable to subject every such applicant to a satisfactory sight test.

The standards of vision necessary for driving mechanically propelled vehicles are not the same for all classes of drivers. The visual requirements of one who drives his own car and of a driver of a hackney vehicle are different. A driver of his own car can choose his own route, his own time, and the pace at which he goes. A driver of a hackney vehicle is not a free agent in these matters; he must go by such route, at such time, and at such pace as his employer directs. The responsibilities of motor omnibus and tramcar drivers are greater than those of drivers of other forms of motor conveyance. The former carry in their vehicles a large number of passengers, and proceed along fixed routes at stated times. The vehicles which they steer are larger and heavier, and as a rule the drivers are less adequately protected from the effects of mist, rain, and dust. Tramcars proceed along fixed lines, and do not require to be steered from side to side amongst surrounding traffic, like motor omnibuses. In 1917 motor omnibuses and tramcars were responsible for 36 per cent. of the fatal, and 42 per cent. of the non-fatal motor accidents reported in London (see tables, pages 32 and 33.)

The visual requirements of hired drivers, other than the drivers of hackney vehicles, such as private chauffeurs and the drivers of trade and commercial cars have also to be considered.

The Council is of opinion that every applicant for a licence to drive a motor car or motor cycle, such as is now granted by a County or Borough Council, should be required to show his ability to steer such a vehicle round corners and to avoid obstacles. This would afford a rough test of his visual powers, though it would not exclude a person who has lost the sight of one eye or has low acuity of vision, or night blindness. No person who from anv cause has double vision should be granted a licence.

If a regulation to this effect is instituted, and licences are granted only to those persons who show themselves competent to drive, it will be necessary to grant temporary permits to those learning to 
drive. It should be made obligatory for anyone using such a. permit to be accompanied by a licensed driver, except in the case of a motor cyclist.

The Council is also of opinion that certificates should be granted to applicants stating their visual fitness to drive certain classes of motor vehicles, after having had their sight tested by ophthalmic surgeons appointed for that purpose. These certificates should be divided into three grades, $\mathrm{A}, \mathrm{B}$, and $\mathrm{C}$.

Grade A would certify the holder's visual capacity to drive any kind of motor vehicle.

Grade B would certify the holder's visual capacity to drive any kind of motor vehicle other than motor omnibuses or tramcars.

Grade C would certify the holder's visual capacity to drive motor tramcars.

For Grade A certificate an applicant, in addition to manifesting his ability to steer a motor car satisfactorily in daylight, should be required, in a trial trip at night, to show himself capable of driving in dim light and under varying degrees of illumination.

In the absence of further data than the Council possesses at present it suggests that the vision required for a Grade A certificate should be fixed at a high standard and considers that visual acuity of a standard equal to $6 / 9$ in one eye and 6/24 in the other, without the aid of glasses, should be adopted. It is not necessary to specify which eye should have the better vision. Every applicant should have in each eye a full field of vision as tested by hand movement, or in case of doubt by a perimeter, and should have no manifest squint, nor double vision.

Grade B certificate differs from Grade A certificate in allowing the applicant to use glasses to reach the required visual standard. The presence of a squint should not disqualify.

For Grade C certificate the same visual standards should be required as for Grade A certificate, but the driving tests must be made on a tramcar instead of on a motor car.

If these certificates of sight for motor drivers be instituted the Council thinks it should be compulsory for every driver of a mechanically propelled hackney vehicle to obtain the appropriate certificate before being granted a licence to drive.

The Council would here point out that in setting up standards of vision for hackney cab drivers it must be recognized that some persons have a greater capacity than others for overcoming the disadvantages occasioned by a visual defect. This is due to several factors of which the most important are: the varying degrees of rapidity with which individuals respond to a visual stimulus, and the influence of previous training. It is as some rough practical test of the former that the Council recommends a daylight trial trip as well as the direct vision test, and in connection with the latter it recommends 
that some leniency might be shown as to the standard of central acuity of vision required for the renewal of licences to hackney cab drivers of long experience. The Council considers that licences in such cases might be renewed when the standard of central vision is equal to $6 / 12$ in one eye and $6 / 36$ in the other, with or without glasses.

In view of the large number of accidents occurring in connection with motor vehicles driven by hired drivers, other than licensed hackney carriage drivers, and especially in connection with trade and commercial cars, which in 1917 were responsible for 33 per cent. of the fatal and 19 per cent. of the non-fatal motor accidents in London (vide pages 32 and 33), the Council urges that all employers should be strongly advised to engage only such drivers as have obtained a Grade A or a Grade B certificate.

\section{5.-Summary of Recommendations}

In conclusion the Council's recommendations may be summarized as follows :

I. That before a licence is granted by a County or Borough Council to an applicant to drive a mechanically propelled vehicle along the public roads such applicant be required to show his ability to steer a motor car round corners and to avoid obstacles.

II. That before such a licence be renewed the applicant be required to sign a statement that since the licence was granted he has not suffered from any physical disability likely to interfere with his driving capacity.

III. That if a licensed driver who suffers from some visual defect meet with an accident attributable in any way to that defect, he shall be liable to have his licence taken from him, or endorsed, as may be considered desirable in accordance with the circumstances of the case.

IV. That special sight test certificates for drivers of motor vehicles be instituted, and granted to applicants whose sight has been tested by ophthalmic surgeons appointed for the purpose, these certificates to be of three grades :

Grade A, certifying the holder's visual capacity to drive any kind of motor vehicle.

Grade B, certifying the holder's visual capacity to drive any kind of motor vehicle other than a motor omnibus or tramcar.

Grade C, certifying the holder's visual capacity to drive a motor tramcar.

For Grade A certificate :

1. Every applicant, in addition to manifesting his ability to steer a motor car satisfactorily in daylight, should be required, in a trial trip at night, to show himself capable of driving in dim light and under varying degrees of illumination. 
2. In an examination by an ophthalmic surgeon he should show :

(a) Visual acuity of $6 / 9$ in one eye and $6 / 24$ in the other eye without the aid of glasses.

(b) A full field of vision in each eye.

(c) No manifest squint.

(d) No double vision.

For Grade B certificate :

1. Every applicant, in addition to manifesting his ability to steer a motor car satisfactorily in daylight, should be required, in a trial trip at night, to show himself capable of driving in dim light and under varying degrees of illumination.

2. In an examination by an ophthalmic surgeon he should show :

(a) Visual acuity of $6 / 9$ in one eye, and $6 / 24$ in the other eye with glasses if necessary.

(b) A full field of vision in each eye.

(c) No double vision.

For Grade C certificate :

1. Every applicant should be required in a trial trip to show himself capable of driving a motor tramcar by day and by night under varying degrees of illumination.

2. In an examination by an ophthalmic surgeon he should reach the same visual standards as for a Grade A certificate.

V. That an applicant for a licence to drive a mechanically propelled hackney carriage be required to obtain the appropriate sight test certificate before such licence be granted.

An applicant for a renewal of licence to drive a hackney motor cab who is an experienced driver might, however, be granted such a renewal with a lower standard of central acuity of vision, viz., $6 / 12$ in one eye and $6 / 36$ in the other with or without glasses.

VI. That owners of mechanically propelled vehicles, other than hackney carriages, be strongly advised to employ as drivers only those who have obtained a Grade A or Grade B certificate.

VII. That temporary permits be granted to those learning to drive mechanically propelled vehicles. When driving motor cars along the public roads, the holders of such permits must be accompanied by a licensed driver. 